\title{
Oncology patients' communication experiences during COVID-19: comparing telehealth consultations to in-person visits
}

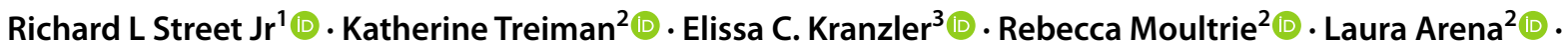 \\ Nicole Mack ${ }^{2}$ (1) $\cdot$ Reese Garcia ${ }^{4}$ (1)
}

Received: 2 September 2021 / Accepted: 2 February 2022 / Published online: 9 February 2022

(c) The Author(s), under exclusive licence to Springer-Verlag GmbH Germany, part of Springer Nature 2022

\begin{abstract}
Purpose The COVID-19 pandemic created significant disruptions in cancer care, much of which was transitioned to telehealth. Because telehealth alters the way clinicians and patients interact with one another, this investigation examined patients' perceptions of their communication with clinicians during the pandemic.

Method Patients were recruited from the Cancer Support Community, Fight Colorectal Cancer, and a market research firm to participate in an online survey. In addition to demographic and health-related information, respondents completed measures of patient-centered communication and evaluated how their communication in telehealth sessions compared with in-person visits.

Results From October to December 2020, 227 respondents (65.6\% female, 64.6\% Non-Hispanic White, 33.5\% had 6 or more telehealth sessions, $55 \%$ were 50 or older) reported having some of their cancer care provided via telehealth. Respondents who were of racial/ethnic minorities, male, had more telehealth sessions, or had poorer mental health reported less patientcentered communication with clinicians. Most patients thought communication in telehealth sessions was "about the same" as in-person visits with respect to good communication (59\%). However, patients thinking communication in telehealth sessions was "better" than in-person visits were more likely to be Hispanic (49\%), Non-Hispanic Black (41\%), under 50 years of age (32\%), male (40\%), and had more telehealth sessions (34\%).

Conclusion Respondents reporting less patient-centered communication during the pandemic —e.g., persons of racial/ethnic minorities and males-were also more likely to evaluate communication in telehealth sessions as better than in-person visits. Further research is needed to understand reasons underlying this finding. Cancer care clinicians should take into account patient preferences regarding telehealth care, which may be particularly important for racial and ethnic minority patients.
\end{abstract}

Keywords COVID-19 pandemic $\cdot$ Patient-centered communication $\cdot$ Telehealth $\cdot$ Patient preferences $\cdot$ Health disparities

\section{Introduction}

The COVID-19 pandemic has led to significant disruptions, changes, or delays in cancer screening, diagnosis, and treatment across multiple cancers [1-3]. In addition to routine management of patient care, coping with the pandemic

Richard L Street Jr

r-street@tamu.edu

1 Texas A\&M University, College Station, TX, USA

2 RTI International, Raleigh, NC, USA

3 Cancer Support Community (formerly), currently Fors Marsh Group, Arlington, VA, USA

4 Fight Colorectal Cancer, Springfield, MO, USA challenged clinicians' ability to have informative, compassionate, and supportive interactions with their patients to reduce risk of infection, cope with uncertainty, manage symptoms, and adjust to changes in treatment plans [4]. A recent study [5] highlighted the importance of patientcentered communication in the context of the pandemic. In that sample, the adverse effects of COVID-19-related fear on cancer patients' hopelessness were buffered when patients perceived their clinicians' communication as clear and empathetic.

To reduce the risk of COVID-19 exposure among patients and their clinicians, cancer care teams rapidly shifted many appointments from in-person visits to telehealth sessions [6-8]. Of interest in this study is how oncology patients perceive the quality of their communication with clinicians 
during the pandemic and how their communication during telehealth sessions - characterized by synchronous clinicianpatient communication-compares with communication during in-person visits.

This is an important topic for several reasons. Patientcentered communication in cancer care is characterized by effective information exchange, fostering healing relationships, helping patients manage uncertainty and emotions, and making quality treatment decisions [9]. Patient-centered interactions are not only a requirement for high-quality cancer care, they also can contribute to better cancer care outcomes $[10,11]$.

Current evidence is mixed regarding patient experiences with telehealth sessions compared with in-person visits. On the one hand, some surveys have indicated that most oncology patients are satisfied with their telehealth sessions with respect to the care received and their communication with clinicians [8, 12-14]. Patient satisfaction with telehealth has been attributed to protecting patients and clinicians from COVID-19 infections, maintaining continuity of care, reducing treatment burden, creating the convenience of consultations from home, avoiding transportation hassles for in-person appointments, and creating the ability to engage a caregiver or support person for a telehealth session [3, 15-17].

On the other hand, patients and clinicians have expressed concerns that the move to telehealth has or will lead to less effective clinician-patient communication. Some are worried that telehealth sessions will make it more difficult for providers to express caring and support [18], which may weaken the clinician-patient relationship by diminishing nonverbal connection and in-person "presence" [17, 19]. Others are concerned telehealth may create delays in getting needed information [20]. Also, some patients have experienced challenges during video telehealth sessions, such as having limited internet bandwidth (especially among patients in rural communities) $[18,21]$, frustration with using the technology $[8,21]$, and questioning the effectiveness of virtual physical examinations for symptomatic patients [20]. As highlighted in a recent study, although most gynecological and breast cancer participants expressed satisfaction with their telehealth sessions, a majority also reported that the quality of care was not as good as in-person visits [13].

Additionally, certain groups of patients may have had better (or worse) communication experiences since the start of the pandemic. For example, older oncology patients have reported less satisfaction with communication in telehealth sessions, in part because of lack of familiarity with or frustration when using the technology $[8,21]$. Regarding gender, of two surveys conducted in Australia during the pandemic, one survey reported males were generally more supportive of telehealth compared with females [22], whereas the other survey found males had poorer telehealth experiences [23].
Outcomes also may differ by race and ethnicity. A recent survey of patients at a gastroenterology clinic indicated that most Black and White patients reported their telehealth sessions were as good or better when compared with in-person visits; however, Black patients were more likely to report technological problems [24]. By contrast, a prepandemic survey of primary care patients in California observed that Black respondents were more likely to choose both video and telephone sessions over in-person visits compared with Hispanic, White, and Asian respondents [25].

Health status also may influence oncology patients' communication experiences during the pandemic. In one international survey (with respondents mainly from the USA and Canada), most oncology patients (83\%) were satisfied with their telehealth experience, although patients in the early stages of treatment and those with the shortest duration of treatment were less likely to be satisfied with virtual oncology appointments [8]. In an Australian study of telehealth users (not limited to oncology), patients reporting more anxiety were more likely to have poorer telehealth experiences [23]. However, some cancer care providers have argued that, in the absence of in-person visits, telehealth helps address the psychological challenges faced by cancer survivors during the pandemic by providing a mechanism for continuity of mental health support services [26].

The adjustments made by cancer care providers during the pandemic highlight the need for gathering patients' perceptions of the quality of their communication with clinicians and how their communication in telehealth sessions (video or phone) compares with communication in in-person visits. This study explored two research questions: How do oncology patients assess the quality of their communication with clinicians during the pandemic, and do these evaluations vary by patients' sociodemographic and health-related characteristics? How do oncology patients compare the quality of their communication in telehealth sessions to communication in in-person visits?

\section{Methods}

\section{Participants}

From October to December 2020, oncology patients who had received treatment during the pandemic were recruited for an online survey of their cancer care experiences since the pandemic started. Survey participants were recruited through nonprofit cancer support organizations, the Cancer Support Community and Fight Colorectal Cancer, and through a market research firm. Eligibility criteria included having a cancer diagnosis (any cancer type), aged 18 or older, English speaking, and having received any type of cancer treatment in 2020. Survey respondents were offered 
the chance to win a $\$ 75$ gift card (20 survey respondents were randomly selected).

\section{Measures}

Quality of clinician-patient communication was assessed with two sets of measures. The Patient-Centered Communication-Cancer-6 Items (PCC-CA-6) [27] consists of 6 items on which patients self-assess their communication with clinicians since the pandemic began across key domains of patient-centered communication: information exchange, fostering healing relationships, responding to emotions, managing uncertainty, making decisions communication, and enabling self-management. The measure is grounded in the National Cancer Institute's 6-function model of patient-centered communication in cancer care [9]. Items are averaged to create a composite patient-centered communication score. The survey also included 3 singleitem measures where respondents were asked, "Compared to in-person visits, how well do your cancer care doctors and other healthcare professionals communicate (show caring and support, provide the information you need) during telehealth sessions?" Response options included Much better, Somewhat better, About the same, Somewhat worse, or Much worse. For each domain, response options were collapsed to create a 3-level variable for which responses were Better, About the same, or Worse.

Additional survey measures included patient's demographic characteristics (age, gender, education, race, and ethnicity), time since diagnosis, type of cancer, and number of telehealth sessions. Mental and physical health status was measured using 2 items from the Patient-Reported Outcomes Measurement Information System (PROMIS) [28]: "In general, how do you rate your mental health, including your mood and ability to think?" and "In general, how do your rate your physical health?" Response options included Poor, Fair, Good, Very Good, or Excellent.

\section{Data analysis}

$T$ tests and, as applicable, analysis of variance (ANOVA) were used to examine bivariate relationships between participant characteristics and patient-centered communication to determine potential covariates for the final multivariable model with patient-centered communication ratings as the outcome. Significant candidate variables $(p<0.01)$ and other variables chosen based on substantive knowledge of patient-centered communication were selected for the final linear model. These variables included number of telehealth sessions, gender, age, combined race and ethnicity, mental health rating, and physical health rating. The final model was evaluated for adherence to assumptions of normality and homoscedasticity of which the assumptions were verified. All testing and modeling were conducted using SASv9.4.

\section{Results}

During the recruitment period (October to December, 2020), 317 patients completed the survey. Of these respondents, $90(28 \%)$ had never used telehealth and were excluded in further analyses. The respondents who were excluded were more likely to be non-Hispanic White and older (Table 1). The final group of respondents was mostly female (66\%) and Non-Hispanic White (64\%), and half were college educated. Colorectal and lung cancer patients comprised $60 \%$ of the respondents, who otherwise were diverse with respect to age, types of cancer, time since diagnosis, and health status (Table 1).

Table 2 presents the overall and subgroup findings of how respondents evaluated their communication with clinicians since the beginning of the pandemic.

\section{Patient-centered communication}

Respondents reporting less patient-centered communication with clinicians tended to be male (mean $=3.6$ of 5 point scale vs. 3.9 for females, $p=.001$ ), younger ( means $=3.5,3.7,3.8$, and 4.1, respectively, for ages $18-34,35-49,50-64$, and 65 and older, $p=.02$ ), and to have had more telehealth sessions (mean $=3.5$ for 6 or more telehealth sessions vs. 3.9 for those having 5 or fewer, $p=.0005$ ). Respondents rating clinicians' communication lower also reported poorer mental health (means $=3.1$ and 3.5 for those reporting poor and fair mental health vs. means of 4.1 and 4.2 for those rating their mental health as very good or excellent, $p<0001$ ). The same pattern was also observed for respondents' ratings of physical health (see Table 2). Hispanic (mean=3.3), NonHispanic Black (mean=3.6), and Multiracial/Asian/Other participants (mean=3.2) evaluated their communication with clinicians less favorably compared with Non-Hispanic Whites (mean $=4.1, p<.0001$ ). Patient-centered communication ratings did not vary as a function of respondents' education, cancer type, and time since diagnosis (see Table 2).

In multivariable analyses, the strongest predictors of less patient-centered communication were race and ethnicity (specifically, Hispanic and Multiracial/Asian/Other respondents) and those reporting poorer mental health (both $p<.0001$ ) (Table 3).

\section{Telehealth sessions as compared with in-person visits}

Table 4 presents the results comparing communication in telehealth sessions to that of in-person visits. Most respondents 
Table 1 Participant characteristics by ever use of telehealth $(N=317)$

\begin{tabular}{|c|c|c|c|}
\hline Characteristics & $\begin{array}{l}\text { Yes } \\
N(\%)\end{array}$ & $\begin{array}{l}\text { No } \\
N(\%)\end{array}$ & $p$ value \\
\hline Overall & $227(100.0 \%)$ & $90(100.0 \%)$ & \\
\hline \multicolumn{4}{|l|}{ Gender } \\
\hline Female & $149(65.6 \%)$ & $57(63.3 \%)$ & 0.7520 \\
\hline Male & $77(33.9 \%)$ & $32(35.6 \%)$ & \\
\hline Other & $1(0.4 \%)$ & $0(0.0 \%)$ & \\
\hline Prefer not to answer & $0(0.0 \%)$ & $1(1.1 \%)$ & \\
\hline \multicolumn{4}{|l|}{ Age } \\
\hline $18-34$ & $20(8.8 \%)$ & $5(5.6 \%)$ & $p<0.0001$ \\
\hline $35-49$ & $83(36.6 \%)$ & $16(17.8 \%)$ & \\
\hline $50-64$ & $93(41.0 \%)$ & $37(41.1 \%)$ & \\
\hline $65+$ & $31(13.7 \%)$ & $32(35.6 \%)$ & \\
\hline \multicolumn{4}{|l|}{ Race/ethnicity } \\
\hline Hispanic & $47(20.8 \%)$ & $3(3.3 \%)$ & 0.0019 \\
\hline NH White & $146(64.6 \%)$ & $73(81.1 \%)$ & \\
\hline NH Black & $22(9.7 \%)$ & $9(10.0 \%)$ & \\
\hline NH Asian, AI, NHPI, multiracial/other & $11(4.9 \%)$ & $5(5.6 \%)$ & \\
\hline \multicolumn{4}{|l|}{ Education } \\
\hline HS graduate or GED or less & $22(9.7 \%)$ & $12(13.3 \%)$ & 0.7286 \\
\hline Some college & $41(18.1 \%)$ & $17(18.9 \%)$ & \\
\hline Associate degree in college or technical school degree & $51(22.5 \%)$ & $13(14.4 \%)$ & \\
\hline College or advanced or postgraduate degree & $113(49.8 \%)$ & $48(53.3 \%)$ & \\
\hline \multicolumn{4}{|l|}{ Cancer type } \\
\hline Colon or rectal cancer & $93(41.0 \%)$ & $27(30.0 \%)$ & 0.1925 \\
\hline Breast cancer & $48(21.1 \%)$ & $23(25.6 \%)$ & \\
\hline Other & $86(37.9 \%)$ & $40(44.4 \%)$ & \\
\hline \multicolumn{4}{|l|}{ Time since diagnosis } \\
\hline$<1$ year & $78(34.5 \%)$ & $25(27.8 \%)$ & 0.2202 \\
\hline 1 year to less than 2 years & $59(26.1 \%)$ & $23(25.6 \%)$ & \\
\hline 2 years to less than 5 years & $48(21.2 \%)$ & $23(25.6 \%)$ & \\
\hline \multirow[t]{2}{*}{$5+$ years } & $41(18.1 \%)$ & $19(21.1 \%)$ & \\
\hline & Mean (Std) & Mean (Std) & $p$ value \\
\hline Mental health & $3.07(1.01)$ & $3.36(1.08)$ & $0.0273^{*}$ \\
\hline Physical health & $2.84(0.98)$ & $3.06(0.84)$ & 0.0645 \\
\hline
\end{tabular}

reported that clinicians communicated as well during telehealth sessions as they did in in-person visits (59\%), including getting needed information $(67 \%)$ and receiving care and support (69\%). However, these evaluations varied significantly across subgroups of patients. Interestingly, although the majority of respondents in most subgroups rated communication in telehealth sessions as "About the Same" as in-person visits, a high percentage of respondents in certain subgroups rated telehealth to be better than in-person visits. Patients more likely to rate their overall communication as better in telehealth sessions than in-person visits were male, younger, and those who had 6 or more telehealth sessions. This same pattern held true for respondents' perceptions of getting needed information and receiving care and support from clinicians (Table 4).
With respect to race and ethnicity, Non-Hispanic Whites generally rated communication in telehealth sessions and in-person visits as the same across the 3 communication domains (67\% to $81 \%$ ). However, higher proportions of Hispanic (48.9\%), Non-Hispanic Black (40.9\%), and Multiracial/Asian/Other respondents $(45.5 \%)$ rated their overall communication via telehealth sessions as better than inperson visits compared with non-Hispanic Whites $(11 \%$, $p<.0001)$. The same pattern was observed for telehealth vs. in-person visits comparisons for how well clinicians showed caring and support and provided needed information (see Table 4). In terms of health status factors, respondents' evaluations of communication in telehealth sessions as compared with in-person visits did not vary as a function of selfreported mental or physical health or of time since diagnosis. 
Table 2. Patient-centered communication (PCC) scores by subgroups among telehealth users $(N=227)$

\begin{tabular}{|c|c|c|}
\hline & Overall PCC & \\
\hline & Mean (SD) & $p$ value $^{\mathrm{c}}$ \\
\hline Overall & $3.8(0.77)$ & \\
\hline Number of telehealth sessions & & 0.0005 \\
\hline 5 or less & $3.9(0.76)$ & \\
\hline 6 or more & $3.5(0.72)$ & \\
\hline Gender $^{\mathrm{a}}$ & & 0.0014 \\
\hline Female & $3.9(0.78)$ & \\
\hline Male & $3.6(0.71)$ & \\
\hline Other & $3.5()$. & \\
\hline Age & & 0.0204 \\
\hline $18-34$ & $3.5(0.48)$ & \\
\hline $35-49$ & $3.7(0.76)$ & \\
\hline $50-64$ & $3.8(0.79)$ & \\
\hline 65 or older & $4.1(0.78)$ & \\
\hline Race/ethnicity ${ }^{\mathrm{b}}$ & & 0.0001 \\
\hline Hispanic & $3.3(0.55)$ & \\
\hline Non-Hispanic White & $4.0(0.71)$ & \\
\hline Non-Hispanic Black & $3.6(0.66)$ & \\
\hline $\begin{array}{l}\text { Non-Hispanic Asian, American Indian, Native Hawaiian or Pacific } \\
\text { Islander, Multiracial/Other }\end{array}$ & $3.2(1.14)$ & \\
\hline Education & & 0.1675 \\
\hline High school graduate or GED or less & $3.8(0.84)$ & \\
\hline Some college & $3.5(0.86)$ & \\
\hline Associate degree in college or technical school degree & $3.8(0.69)$ & \\
\hline College or advanced or postgraduate degree & $3.9(0.75)$ & \\
\hline Cancer type & & 0.6352 \\
\hline Colon or rectal cancer & $3.7(0.74)$ & \\
\hline Breast cancer & $3.9(0.70)$ & \\
\hline Other & $3.8(0.84)$ & \\
\hline Time since diagnosis & & 0.6180 \\
\hline Less than 1 year & $3.7(0.91)$ & \\
\hline 1 year to less than 2 years & $3.7(0.66)$ & \\
\hline 2 years to less than 5 years & $3.9(0.67)$ & \\
\hline 5 or more years & $3.9(0.73)$ & \\
\hline Mental health & & 0.0001 \\
\hline Poor & $3.1(1.03)$ & \\
\hline Fair & $3.5(0.81)$ & \\
\hline Good & $3.8(0.69)$ & \\
\hline Very good & $4.1(0.61)$ & \\
\hline Excellent & $4.2(0.70)$ & \\
\hline Physical health & & 0.0001 \\
\hline Poor & $3.1(0.92)$ & \\
\hline Fair & $3.7(0.71)$ & \\
\hline Good & $3.9(0.72)$ & \\
\hline Very good & $3.9(0.76)$ & \\
\hline Excellent & $4.1(0.57)$ & \\
\hline
\end{tabular}

${ }^{a}$ Answers other than male and female were excluded

${ }^{b}$ For statistical testing, categories were collapsed into 3 categories: Hispanic; Non-Hispanic White and Non-Hispanic Black/Asian; and American Indian, Native Hawaiian or Pacific Islander/Other/Multiracial

${ }^{\mathrm{c}}$ Statistical tests conducted were conducted using ANOVA 
Table 3. Predictors of patient-centered communication (PCC)

\begin{tabular}{|c|c|c|}
\hline \multirow[t]{2}{*}{ Characteristics } & \multicolumn{2}{|l|}{ PCC } \\
\hline & $B(\mathrm{SE})$ & $95 \% C I$ \\
\hline \multicolumn{3}{|l|}{ Number of telehealth sessions } \\
\hline 5 or less telehealth sessions & $0.09(0.11)$ & {$[-0.116,0.303]$} \\
\hline 6 or more telehealth sessions & REF & \\
\hline \multicolumn{3}{|l|}{ Sex } \\
\hline Female & $0.14(0.1)$ & {$[-0.05,0.337]$} \\
\hline Male & REF & \\
\hline Age & $0.005(0.004)$ & {$[-0.003,0.013]$} \\
\hline \multicolumn{3}{|l|}{ Race and ethnicity } \\
\hline Hispanic & $-0.51(0.13)^{* * *}$ & {$[-0.766,-0.259]$} \\
\hline Non-Hispanic Black & $-0.28(0.15)$ & {$[-0.581,0.02]$} \\
\hline Non-Hispanic Other & $-0.73(0.21)^{* * *}$ & {$[-1.144,-0.312]$} \\
\hline Non-Hispanic White & REF & \\
\hline Mental health & $0.20(0.05)^{* * *}$ & {$[0.106,0.303]$} \\
\hline Physical health & $0.04(0.05)$ & {$[-0.058,0.146]$} \\
\hline
\end{tabular}

${ }^{*} p$ value $<.05 ; * * p$ value $<.01 ; * * * p$ value $<.001$

Lastly, patient-centered communication scores were highest for respondents who rated communication in telehealth sessions as about the same as in-person visits. Lower communication scores were reported by patients who either perceived telehealth sessions as better or as worse than inperson visits with respect to overall communication, getting needed information, and receiving care and support (Table 3).

\section{Discussion}

This study examined oncology patients' perceptions of their communication with clinicians during the pandemic, a particularly important topic as many cancer care consultations were transitioned from in-person visits to telehealth sessions. We also explored how patients rated their communication in telehealth sessions compared with in-person visits and whether these judgments varied for different groups of patients. Consistent with other surveys of oncology patients [8, 12, 13, 29], a majority of our respondents were positive about their communication with clinicians and rated communication in their telehealth sessions as "about the same" as in in-person visits. However, there were notable differences across subgroups of patients. We discuss our findings with respect to these divergent communication experiences and the implications of the findings for future research and clinical practice.

Study participants' responses fall roughly within 3 clusters (Figure 1). Cluster 1 consists of patients who provided highly favorable ratings of their communication with clinicians and who found telehealth sessions to be about the same as in-person visits with respect to overall communication, getting needed information, and receiving support. These patients were generally non-Hispanic White, female, older, and had fewer (5 or less) telehealth sessions (Tables 2 and 3). By contrast, respondents in cluster 2 reported less patient-centered communication with clinicians; however, proportionally more of these respondents evaluated their communication in telehealth sessions as better than in inperson visits. These patients tended to be persons of racial and ethnic minority groups (Hispanic, non-Hispanic Black, Multiracial/Asian/Other), male, and those who had 6 or more telehealth sessions.

Lastly, across the entire sample, proportionally fewer respondents reported poorer communication in telehealth sessions compared with in-person visits (18\%), as compared with respondents reporting communication was better (23\%) or the same (59\%). However, there were subgroups of patients in which more than $20 \%$ reported communication in telehealth sessions was poorer than in in-person visits. Cluster 3 comprised respondents who were older than 65 (29\%), non-Hispanic White (22\%), and those reporting poor/ fair physical (24\%) and mental (22\%) health.

While this investigation did not test hypotheses for group differences, our findings align with previous research and point to novel areas for future investigations. First, with respect to race and ethnicity, Non-Hispanic White respondents in our sample fared better in their communication experiences, whether in in-person visits or in telehealth sessions, when compared with respondents of other races and ethnicities. While some research in cancer care settings has found few differences in patients' perceptions of their communication with clinicians as a function of race and ethnicity [30], other studies have reported that racial and ethnic minority groups evaluated their communication in oncology visits less favorably compared with non-Hispanic Whites [31-34]. The more intriguing finding, however, is that almost half of Hispanic (49\%), Black (41\%), and Multiracial/Asian/Other (46\%) respondents in our sample rated their communication in telehealth sessions as better than in in-person visits compared with non-Hispanic Whites (11\%).

One possible explanation for this finding is that the poorer experiences many racial and ethnic minority patients have when communicating in-person with clinicians-whether because of more awkward interactions [35], perceived prejudice [36], or implicit bias [37] —are mitigated to some extent in telehealth sessions compared with in-person visits. Alternatively, other elements of the communication context may influence evaluative comparisons. For example, since the pandemic, Black and Latino patients have been more likely to use telehealth services compared with non-Hispanic Whites (especially via telephone) [24, 25, 38]. Consequently, even if communication experiences are roughly comparable in telehealth sessions as compared with in-person visits, the 


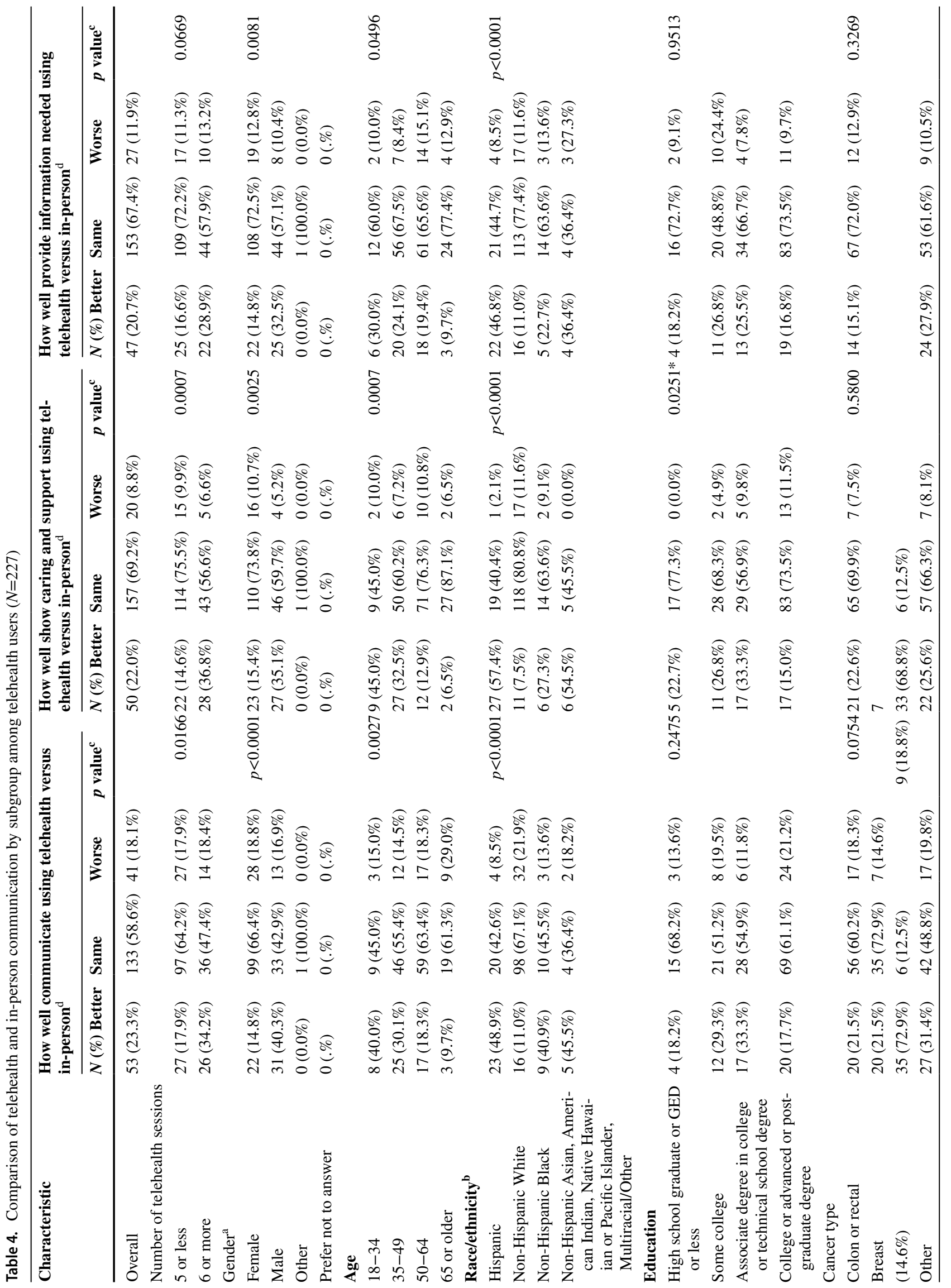




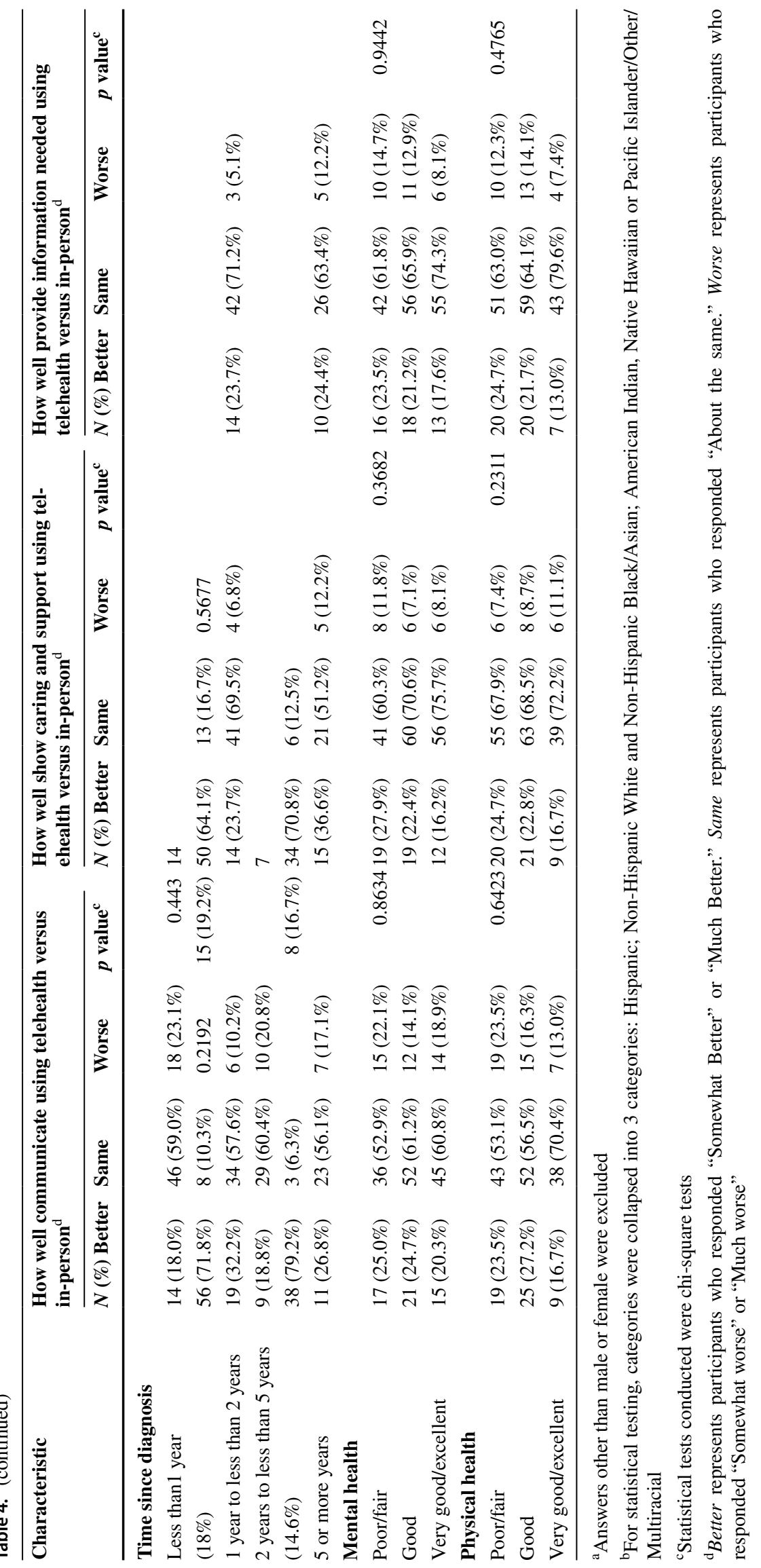


Figure 1. Clusters of responses for quality of communication and comparing telehealth to in-person. $* P C C$, patientcentered communication scores. **Respondents with poorer mental and physical health had lower PCC ratings. Non-Hispanic Whites and older patients had higher PCC ratings

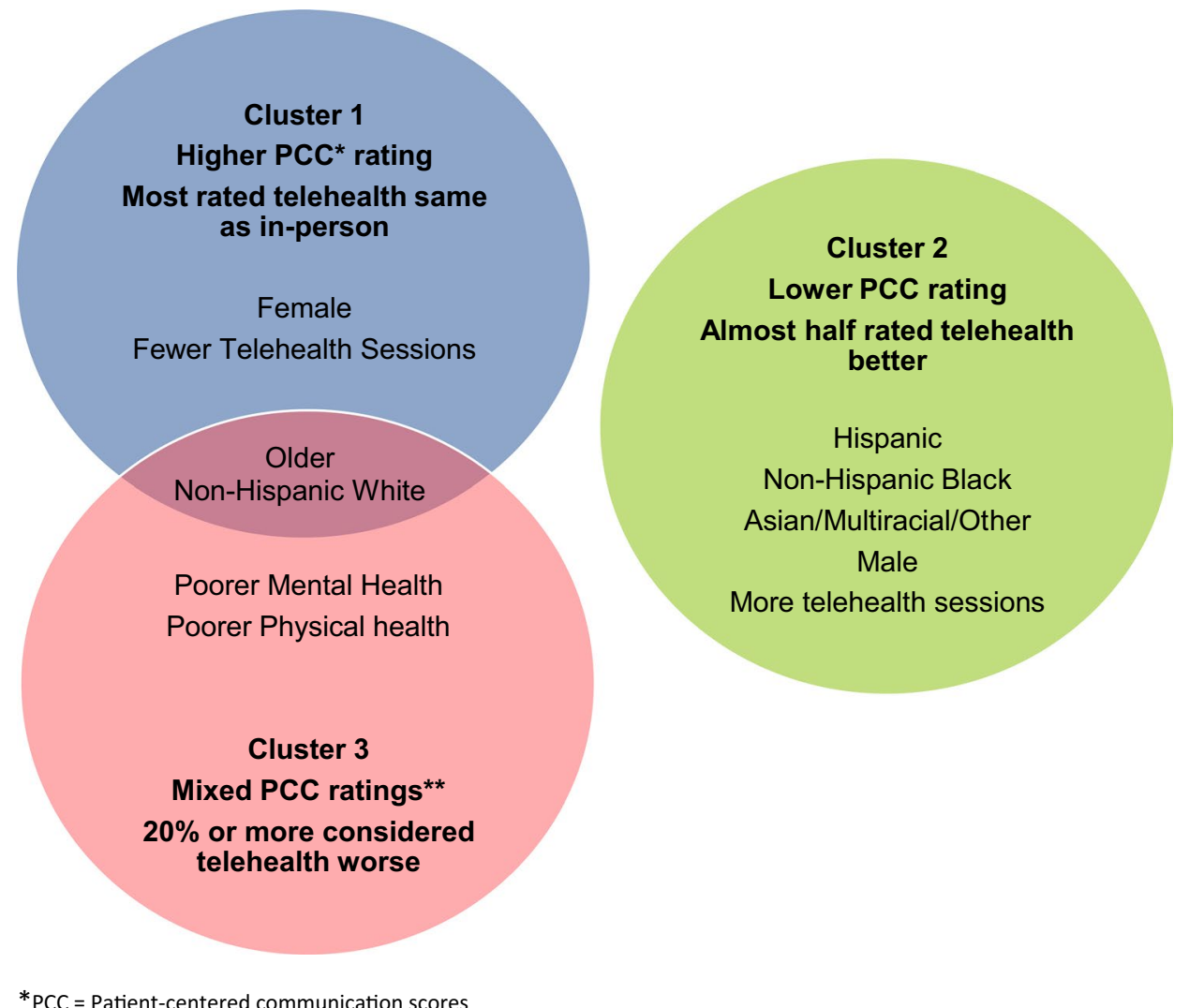

${ }^{*}$ PCC $=$ Patient-centered communication scores

**Respondents with poorer mental and physical health had lower PCC ratings. Non-Hispanic Whites and older patients had higher PCC ratings. aforementioned benefits of having a consultation at home, and not having to travel to the clinic, arrange for childcare, pay for parking, have long wait times at the clinic, and fewer interactions with staff and security may make telehealth sessions a more favorable communicative experience [15-17].

Cluster 3 comprised patients proportionally more likely to evaluate their communication in telehealth sessions as worse compared with in-person visits and provided mixed ratings of their communication with clinicians. For example, some respondents in cluster 3, such as non-Hispanic Whites and patients aged 50 or older, overlap with cluster 1 in that these respondents provided higher ratings to their communication with clinicians but, compared with other groups, were proportionally more likely to report communication in telehealth sessions was worse than in in-person visits $(22 \%$ and $21 \%$, respectively). Unique to Cluster 3 were patients reporting poorer mental and physical health. These respondents gave lower ratings to their communication with clinicians and a sizeable proportion thought communication in telehealth sessions was worse than in in-person visits $(22 \%$ and $25 \%$, respectively) (Table 3 ). The poorer assessment of communication in telehealth sessions by older patients is consistent with other surveys in oncology since the start of the pandemic [8, 39]. Additionally, prepandemic surveys also found oncology patients with poorer health status reported less favorable communication experiences [31]. However, the other differences are harder to explain. Based on our findings and given that telehealth is likely to remain on option for cancer care services, future research should examine why certain cancer patients who have had less than optimal communication experiences with clinicians may respond favorably to telehealth sessions rather than traveling to clinics for in-person visits.

Finally, our findings point to several areas for further investigation. Future research should include more racially/ ethnically diverse and vulnerable populations, particularly within safety net settings. Perceived bias and systemic structures can lower the quality of patients' communication experiences in these settings, an unintended consequence of which may make telehealth a more favorable option for consultations. Further study is also needed to examine the clinical and health-related consequences of offering patients a choice for in-person visits or telehealth sessions. For example, a prepandemic systematic review [40] concluded that patient preferences for cancer treatment can significantly influence treatment adherence and outcomes. Would accommodating patient preferences for either telehealth sessions or in-person visits enhance patients' cancer care experiences, 
such as greater patient satisfaction and perceived control? Moreover, if choosing a telehealth option for certain cancer services, what modality (video or telephone) would patients desire? A recent survey at a large multispecialty, outpatient clinic [41] reported that a majority of patients were very likely to use telehealth for patient education, preparing for visits, and reviewing test results. However, compared with patients who had a telephone session, those who participated in a video session were more likely to report preferences for using telehealth for education, care plan discussions, longterm health issues, and mental health.

\section{Study limitations}

Our study had several limitations. First, although we found subgroup differences-such as race and ethnicity, and gender-generalizability of the findings is limited because the sample was largely non-Hispanic White, female, and college educated. Second, our study was conducted before COVID-19 vaccines were readily available. Thus, for many patients in this study, telehealth was the only option for certain cancer care services. Now that clinics are returning to in-person visits, future research should assess patient experiences and preferences when both telehealth and in-person visits are available. Third, because respondents were asked to participate via an online survey, the sample may have overrepresented people accustomed to using the internet for everyday activities, which could include having telehealth for some cancer care services. Fourth, we did not ask participants about the content and purpose of their oncology visits (whether with telehealth sessions or in-person visits) or the number of telehealth sessions that were delivered via video relative to telephone. For example, symptomatic patients likely have stronger preferences for in-person visits, [20] whereas telehealth may be a viable media choice for followup care. Finally, we did not examine whether patients were offered a choice (video or telephone) for their telehealth sessions. This is an important topic for future research as the communicative experiences associated with video visits are significantly different from telephone sessions with respect to visual connection and engagement.

\section{Clinical implications}

The pandemic may serve as the impetus for structural changes in cancer care to allow, even encourage, telehealth sessions for some cancer care services [42]. Our findings align with other findings indicating that many patients (and healthcare professionals) would like telehealth to remain an option for future cancer care [12, 13, 21, 43]. Cancer care consultations for which telehealth sessions may be very appropriate include some initial visits, genetic counseling, psychological and supportive care, symptom management, patient education, and nutrition counseling [44]. Consultations for complex treatment recommendations, delivering bad news, and invasive treatment are arguably less appropriate for telehealth sessions [43]. However, when the threat of contracting COVID-19 wanes, patients who were tolerant of virtual cancer care during the pandemic may have preferences for returning to usual care [45]. This suggests patients should be offered a choice for modality of service, assuming appropriate care can be provided.

\section{Conclusion}

Oncology patients in this study generally rated their communication with clinicians favorably since the start of the pandemic and thought communication in telehealth sessions was "about the same" as in in-person visits with respect to overall communication and getting needed information, care, and support. However, certain groups of patients had very different communication experiences. Racial and ethnic minority groups and male patients reported receiving less patient-centered communication during the pandemic. Yet, these same patients were more likely to evaluate communication favorably in telehealth sessions than in in-person visits. Future research should explore the extent to which and why oncology patients who report less patient-centered communication with clinicians may in turn respond more favorably to telehealth sessions as compared with in-person visits. Clinicians should consider patient preferences for telehealth care as compared with in-person care, which may be particularly important for racial and ethnic minority patients.

Acknowledgements This study was conducted in collaboration with the Cancer Support Community and Fight Colorectal Cancer. We would like to thank the survey respondents and who shared their stories. We would also like to thank Jeffrey Novey for editorial support.

Author contribution RS, KT, RM, and EK were involved in the design of the study. KT, EK, RG, and RM coordinated the procedures of the study. RS, KT, and NM performed the data analyses. RS, KT, and LA drafted the manuscript. All authors critically revised the manuscript and approved the final manuscript.

Funding This research was funded through a Patient-Centered Outcomes Research Institute (PCORI) Eugene Washington Engagement Award (EA \# 14460).

Data availability Information about data availability can be provided by contacting Dr. Katherine Treiman (ktreiman@rti.org).

\section{Declarations}

Ethics approval The study was reviewed by RTI International's institutional review board (IRB). The IRB determined that the protocol meets the criteria for exempt research. 
Consent to participate A consent process was included as part of the survey.

Consent to publish Not applicable

Conflict of interest The authors declare no competing interests.

Disclaimer The content is solely the responsibility of the authors and does not necessarily represent the official views of the Patient-Centered Outcomes Research Institute.

\section{References}

1. Chan A, Ashbury F, Fitch MI, Koczwara B, Chan RJ, Group MSS (2020) Cancer survivorship care during COVID-19-perspectives and recommendations from the MASCC survivorship study group. Support Care Cancer. 28(8):3485-8. https://doi.org/10. 1007/s00520-020-05544-4

2. Schmidt AL, Bakouny Z, Bhalla S, Steinharter JA, Tremblay DA, Awad MM, Kessler AJ, Haddad RI, Evans M, Busser F, Wotman M, Curran CR, Zimmerman BS, Bouchard G, Jun T, Nuzzo PV, Qin Q, Hirsch L, Feld J, Kelleher KM, Seidman D, Huang HH, Anderson-Keightly HM, Abou Alaiwi S, Rosenbloom TD, Stewart PS, Galsky MD, Choueiri TK, Doroshow DB (2020) Cancer care disparities during the COVID-19 pandemic: COVID-19 and cancer outcomes study. Cancer Cell 38(6):769-770. https://doi. org/10.1016/j.ccell.2020.10.023

3. Patt D, Gordan L, Diaz M, Okon T, Grady L, Harmison M, Markward N, Sullivan M, Peng J, Zhou A (2020) Impact of COVID-19 on cancer care: how the pandemic is delaying cancer diagnosis and treatment for American seniors. JCO Clin Cancer Inform. 4:1059-1071. https://doi.org/10.1200/CCI.20.00134

4. Colomer-Lahiguera S, Ribi K, Dunnack HJ, Cooley ME, Hammer MJ, Miaskowski C, Eicher M (2021) Experiences of people affected by cancer during the outbreak of the COVID19 pandemic: an exploratory qualitative analysis of public online forums. Support Care Cancer. https://doi.org/10.1007/ s00520-021-06041-y

5. Rossi AA, Marconi M, Taccini F, Verusio C, Mannarini S. From fear to hopelessness: the buffering effect of patient-centered communication in a sample of oncological patients during COVID-19. Behavioral Sciences. 2021;11(6). https://doi.org/10.3390/bs110 60087

6. Lonergan PE, Washington Iii SL, Branagan L, Gleason N, Pruthi RS, Carroll PR, Odisho AY (2020) Rapid utilization of telehealth in a comprehensive cancer center as a response to COVID-19: cross-sectional analysis. J Med Internet Res 22(7):e19322. https:// doi.org/10.2196/19322

7. Wosik J, Fudim M, Cameron B, Gellad ZF, Cho A, Phinney D, Curtis S, Roman M, Poon EG, Ferranti J, Katz JN, Tcheng J (2020) Telehealth transformation: COVID-19 and the rise of virtual care. J Am Med Inform Assoc 27(6):957-962. https://doi. org/10.1093/jamia/ocaa067

8. Loree JM, Dau H, Rebic N, Howren A, Gastonguay L, McTaggart-Cowan H, Gill S, Raghav K, De Vera MA (2021) Virtual oncology appointments during the initial wave of the COVID-19 pandemic: an international survey of patient perspectives. Curr Oncol 28(1):671-677. https://doi.org/10.3390/curroncol280100 65

9. Epstein RM, Street RL, Jr. Patient-centered communication in cancer care: promoting healing and reducing suffering. Bethesda, MD; 2007 2007. Report No.: NIH Publication No. 07-6225.
10. Ong LM, Visser MR, Lammes FB, de Haes JC (2000) Doctorpatient communication and cancer patients' quality of life and satisfaction. Patient Educ Couns 41(2):145-156

11. Street RL Jr, Makoul G, Arora NK, Epstein RM (2009) How does communication heal? Pathways linking clinician-patient communication to health outcomes. Patient Educ Couns 74(3):295-301

12. Gutkin PM, Prionas ND, Minneci MO, Allen E, Balazy KE, Rahimy E, Chang DT, Horst KC (2020) Telemedicine in radiation oncology: is it here to stay? Impacts on patient care and resident education. Int J Radiat Oncol Biol Phys 108(2):416-420. https:// doi.org/10.1016/j.ijrobp.2020.06.047

13. Zimmerman BS, Seidman D, Berger N, Cascetta KP, Nezolosky M, Trlica K, Ryncarz A, Keeton C, Moshier E, Tiersten A (2020) patient perception of telehealth services for breast and gynecologic oncology care during the COVID-19 pandemic: a single center survey-based study. J Breast Cancer 23(5):542-552. https:// doi.org/10.4048/jbc.2020.23.e56

14. Desideri I, Francolini G, Ciccone LP, Stocchi G, Salvestrini V, Aquilano M, Greto D, Bonomo P, Meattini I, Scotti V, Scoccianti S, Simontacchi G, Livi L (2021) Impact of COVID-19 on patient-doctor interaction in a complex radiation therapy facility. Support Care Cancer 29(6):2931-2937. https://doi.org/10.1007/ s00520-020-05793-3

15. Knudsen KE, Willman C, Winn R (2021) Optimizing the use of telemedicine in oncology care: postpandemic opportunities. Clin Cancer Res 27(4):933. https://doi.org/10.1158/1078-0432. CCR-20-3758

16. Doyle-Lindrud S (2020) State of eHealth in cancer care: review of the benefits and limitations of eHealth tools. Clin J Oncol Nurs 24(3):10-15. https://doi.org/10.1188/20.CJON.S1.10-15

17. van der Lee ML, Schellekens MPJ (2020) Bridging the distance: continuing psycho-oncological care via video-consults during the COVID-19 pandemic. Psychooncology 29(9):1421-1423. https:// doi.org/10.1002/pon.5468

18. Daggubati LC, Eichberg DG, Ivan ME, Hanft S, Mansouri A, Komotar RJ, D'Amico RS, Zacharia BE (2020) Telemedicine for outpatient neurosurgical oncology care: lessons learned for the future during the COVID-19 pandemic. World Neurosurg. 139:e859-e863. https://doi.org/10.1016/j.wneu.2020.05.140

19. Jiang CY, El-Kouri NT, Elliot D, Shields J, Caram MEV, Frankel TL, Ramnath N, Passero VA (2021) Telehealth for cancer care in veterans: opportunities and challenges revealed by COVID. JCO Oncol Pract. 17(1):22-29. https://doi.org/10.1200/OP.20.00520

20. Heyer A, Granberg RE, Rising KL, Binder AF, Gentsch AT, Handley NR (2021) Medical oncology professionals' perceptions of telehealth video visits. JAMA Netw Open 4(1):e2033967. https://doi.org/10.1001/jamanetworkopen.2020.33967

21. Patt DA, Wilfong L, Toth S, Broussard S, Kanipe K, Hammonds J, Allen V, Mautner B, Campbell N, Dubey AK, Wu N, Neubauer M, Jones BS, Paulson RS (2021) Telemedicine in community cancer care: how technology helps patients with cancer navigate a pandemic. JCO Oncol Pract. 17(1):e11-e15. https://doi.org/10. 1200/op.20.00815

22. Kaambwa B, Ratcliffe J, Shulver W, Killington M, Taylor A, Crotty M, Carati C, Tieman J, Wade V, Kidd MR (2017) Investigating the preferences of older people for telehealth as a new model of health care service delivery: a discrete choice experiment. J Telemed Telecare 23(2):301-313. https://doi.org/10.1177/ $1357633 \times 16637725$

23. Isautier JM, Copp T, Ayre J, Cvejic E, Meyerowitz-Katz G, Batcup C, Bonner C, Dodd R, Nickel B, Pickles K, Cornell S, Dakin T, McCaffery KJ (2020) People's experiences and satisfaction with telehealth during the COVID-19 pandemic in Australia: crosssectional survey study. J Med Internet Res 22(12):e24531. https:// doi.org/10.2196/24531 
24 Serper M, Nunes F, Ahmad N, Roberts D, Metz DC, Mehta SJ (2020) Positive early patient and clinician experience with telemedicine in an academic gastroenterology practice during the COVID-19 pandemic. Gastroenterology. 159(4):1589-91 e4. https://doi.org/10.1053/j.gastro.2020.06.034

25. Reed ME, Huang J, Graetz I, Lee C, Muelly E, Kennedy C, Kim E (2020) Patient characteristics associated with choosing a telemedicine visit vs office visit with the same primary care clinicians. JAMA Netw Open 3(6):e205873. https://doi.org/10.1001/jaman etworkopen.2020.5873

26. Schade EC, Elkaddoum R, Kourie HR (2020) The psychological challenges for oncological patients in times of COVID-19 pandemic: telemedicine, a solution? Future Oncol 16(29):2265-2268. https://doi.org/10.2217/fon-2020-0552

27. Reeve BB, Thissen DM, Bann CM, Mack N, Treiman K, Sanoff HK, Roach N, Magnus BE, He J, Wagner LK, Moultrie R, Jackson KD, Mann C, McCormack LA. Psychometric evaluation and design of patient-centered communication measures for cancer care settings. Patient Educ Couns. 2017.

28. Code Technology. PROMIS Global-10 [Internet]. n.d. [Available from: https://www.codetechnology.com/promis-global-10/?ref= side_nav.

29. Binder AF, Handley NR, Wilde L, Palmisiano N, Lopez AM. Treating hematologic malignancies during a pandemic: utilizing telehealth and digital technology to optimize care. Front Oncol. 2020;10(1183). https://doi.org/10.3389/fonc.2020.01183

30. Song L, Bensen JT, Zimmer C, Sleath B, Blackard B, Fontham E, Su LJ, Brennan CS, Mohler JL, Mishel M (2013) Patient-health care provider communication among patients with newly diagnosed prostate cancer: findings from a population-based survey. Patient Educ Couns 91(1):79-84

31. Treiman K, McCormack L, Wagner L, Roach N, Moultrie R, Sanoff H, Bann C, Street RL Jr, Ashok M, Reeve BB (2018) Factors affecting the communication experiences of newly diagnosed colorectal cancer patients. Patient Educ Couns 101(9):1585-1593

32. Ayanian JZ, Zaslavsky AM, Guadagnoli E, Fuchs CS, Yost KJ, Creech CM, Cress RD, O'Connor LC, West DW, Wright WE (2005) Patients' perceptions of quality of care for colorectal cancer by race, ethnicity, and language. J Clin Oncol 23(27):6576-6586

33. Schumm MA, Ohev-Shalom R, Nguyen DT, Kim J, Tseng CH, Zanocco KA (2020) Measuring patient perceptions of surgeon communication performance in the treatment of thyroid nodules and thyroid cancer using the communication assessment tool. Surgery. https://doi.org/10.1016/j.surg.2020.08.019

34. Gordon HS, Street RL Jr, Sharf BF, Kelly PA, Souchek J (2006) Racial differences in trust and lung cancer patients' perceptions of physician communication. J Clin Oncol 24(6):904-909

35. Street RL Jr, Gordon H, Haidet P (2007) Physicians' communication and perceptions of patients: is it how they look, how they talk, or is it just the doctor? Soc Sci Med 65(3):586-598
36 Burgess DJ, Fu SS, van Ryn M (2004) Why do providers contribute to disparities and what can be done about it? J Gen Intern Med. 19(11):1154-1159

37. Hall WJ, Chapman MV, Lee KM, Merino YM, Thomas TW, Payne BK, Eng E, Day SH, Coyne-Beasley T (2015) Implicit racial/ethnic bias among health care professionals and its influence on health care outcomes: a systematic review. Am J Public Health 105(12):e60-76. https://doi.org/10.2105/AJPH.2015. 302903

38. Campos-Castillo C, Anthony D (2021) Racial and ethnic differences in self-reported telehealth use during the COVID-19 pandemic: a secondary analysis of a US survey of internet users from late March. J Am Med Inform Assoc 28(1):119-125. https://doi. org/10.1093/jamia/ocaa221

39. Patt D, Wilfong L, Kanipe K, Paulson RS. Telemedicine for cancer care: implementation across a multicenter community oncology practice. Am J Manag Care. 2020;26(10 Spec No.):SP330SP2. https://doi.org/10.37765/ajmc.2020.88560

40. Shingler SL, Bennett BM, Cramer JA, Towse A, Twelves C, Lloyd AJ (2014) Treatment preference, adherence and outcomes in patients with cancer: literature review and development of a theoretical model. Curr Med Res Opin 30(11):2329-2341. https:// doi.org/10.1185/03007995.2014.952715

41. Ebbert JO, Ramar P, Tulledge-Scheitel SM, Njeru JW, Rosedahl JK, Roellinger D, Philpot LM. Patient preferences for telehealth services in a large multispecialty practice. J Telemed Telecare. 2021:1357633X20980302. https://doi.org/10.1177/1357633X20 980302

42. Lou E, Teoh D, Brown K, Blaes A, Holtan SG, Jewett P, Parsons H, Mburu EW, Thomaier L, Hui JYC, Nelson HH, Vogel RI (2020) Perspectives of cancer patients and their health during the COVID-19 pandemic. PLoS ONE 15(10):e0241741. https://doi. org/10.1371/journal.pone.0241741

43. Zhang H, Cha EE, Lynch K, Cahlon O, Gomez DR, Shaverdian N, Gillespie EF (2020) Radiation oncologist perceptions of telemedicine from consultation to treatment planning: a mixed-methods study. Int J Radiat Oncol Biol Phys 108(2):421-429. https://doi. org/10.1016/j.ijrobp.2020.07.007

44. Liu R, Sundaresan T, Reed ME, Trosman JR, Weldon CB, Kolevska T (2020) Telehealth in oncology during the COVID-19 outbreak: bringing the house call back virtually. JCO Oncol Pract. 16(6):289-293. https://doi.org/10.1200/OP.20.00199

45. Rodler S, Apfelbeck M, Schulz GB, Ivanova T, Buchner A, Staehler M, Heinemann V, Stief C, Casuscelli J (2020) Telehealth in uro-oncology beyond the pandemic: toll or lifesaver? Eur Urol Focus 6(5):1097-1103. https://doi.org/10.1016/j.euf.2020.05.010

Publisher's Note Springer Nature remains neutral with regard to jurisdictional claims in published maps and institutional affiliations. 